\title{
Tailoring Charge Recombination in Photoelectrodes Using Oxide Nanostructures
}

\author{
landolo, Beniamino; Wickman, Björn; Svensson, Elin; Paulsson, Daniel; Hellman, Anders
}

Published in:

Nano Letters

Link to article, DOI:

10.1021/acs.nanolett.5b05154

Publication date:

2016

Document Version

Peer reviewed version

Link back to DTU Orbit

Citation (APA):

landolo, B., Wickman, B., Svensson, E., Paulsson, D., \& Hellman, A. (2016). Tailoring Charge Recombination in Photoelectrodes Using Oxide Nanostructures. Nano Letters, 16(4), 2381-2386.

https://doi.org/10.1021/acs.nanolett.5b05154

\section{General rights}

Copyright and moral rights for the publications made accessible in the public portal are retained by the authors and/or other copyright owners and it is a condition of accessing publications that users recognise and abide by the legal requirements associated with these rights.

- Users may download and print one copy of any publication from the public portal for the purpose of private study or research.

- You may not further distribute the material or use it for any profit-making activity or commercial gain

- You may freely distribute the URL identifying the publication in the public portal

If you believe that this document breaches copyright please contact us providing details, and we will remove access to the work immediately and investigate your claim 


\title{
Supporting information
}

\section{Tailoring charge recombination in photoelectrodes using oxide nanostructures}

\author{
Beniamino Iandolo ${ }^{1,2}$, Björn Wickman ${ }^{1}$, Elin Svensson ${ }^{1}$, Daniel Paulsson ${ }^{1}$ and Anders \\ Hellman $^{1, *}$ \\ ${ }^{1}$ Department of Physics, Chalmers University of Technology, 41296 Göteborg, Sweden \\ ${ }^{2}$ Center for Electron Nanoscopy, Technical University of Denmark, 2800, Kongens Lyngby, \\ Denmark
}

*Correspondence to: anders.hellman@chalmers.se. 


\section{Electrodes fabrication}

Fe films were deposited on top of ITO coated glass (PGO GmbH, sheet resistance $\leq 20$ $\Omega /$ square) by physical vapor deposition (PVD 225, Kurt. J. Lesker, base pressure $<5 \times 10^{-7}$ mbar), and their thickness was measured in situ using a quartz-crystal microbalance monitor. The Fe films were converted into $\mathrm{Fe}_{2} \mathrm{O}_{3}$ by thermal oxidation in a tube furnace in a $3: 1 \mathrm{~N}_{2}: \mathrm{O}_{2}$ atmosphere. The temperature was ramped from room temperature up to $350{ }^{\circ} \mathrm{C}$ at a rate of $15^{\circ} \mathrm{C}$ $\min ^{-1}$, after which the temperature was kept constant at $350{ }^{\circ} \mathrm{C}$ for a certain time $t_{o x}$. Then, the furnace was allowed to cool down to room temperature naturally. $t_{o x}$ was set to $12 \mathrm{~h}$ for the $\mathrm{Fe}_{2} \mathrm{O}_{3}+\mathrm{TiO}_{2}$ disks, $\mathrm{Fe}_{2} \mathrm{O}_{3}+\mathrm{SiO}_{2}$ disks and $\mathrm{Fe}_{2} \mathrm{O}_{3}+\mathrm{Cu}_{2} \mathrm{O}$ disks samples, and to $6 \mathrm{~h}$ for the $\mathrm{Fe}_{2} \mathrm{O}_{3}+\mathrm{Fe}_{2} \mathrm{O}_{3}$ disks samples. Reference $\mathrm{Fe}_{2} \mathrm{O}_{3}$ samples were fabricated with $t_{o x}=6 \mathrm{~h}$, as well as to $6+6 \mathrm{~h}$ (i.e. two runs each with $t_{o x}=6 \mathrm{~h}$ ). The reference sample shown in all figures in the main manuscript is the $6+6 \mathrm{~h}$ oxidized sample, which showed slightly better $j_{\text {photo }}$ than the $12 \mathrm{~h}$ sample (see Figure S4).

Hole-mask colloidal lithography was employed to deposit $\mathrm{Ti}, \mathrm{Cu}, \mathrm{Fe}$ or $\mathrm{SiO}_{2}$ nanodisks on top of the $\mathrm{Fe}_{2} \mathrm{O}_{3}$ films (average disk diameter $40 \mathrm{~nm}$, disk thickness $5 \mathrm{~nm}$, surface coverage ranging from 0.01 to 0.21 ). First, the films were cleaned in ultrasonic bath in acetone and isopropanol for 10 minutes each, then under ozone flow (FHR UVOH 150) for $10 \mathrm{~min}$. Then, a $240 \mathrm{~nm}$ thick layer of polymethyl metacrylate (PMMA) was spun on top of $\mathrm{Fe}_{2} \mathrm{O}_{3}$, followed by soft baking $\left(170{ }^{\circ} \mathrm{C}, 10 \mathrm{~min}\right.$ on hotplate). The PMMA layer was ashed for $5 \mathrm{~s}$ in directional $\mathrm{O}_{2}$ plasma (Plasma Therm BatchTop, $5 \mathrm{~s}, 50 \mathrm{~W}, 250 \mathrm{mTorr}$ ) in order to increase its hydrophilicity. A 5\% weight solution of aluminum chloride hydrate $(\mathrm{ACH})$ was pipetted and adsorbed on the surface for $60 \mathrm{~s}$, followed by rinsing with high resistance (Milli-Q) water and blow-drying with a $\mathrm{N}_{2}$ stream. Then, a $0.1 \%$ weight solution of polystyrene (PS) nanospheres was pipetted and adsorbed, also for $60 \mathrm{~s}$, prior to rinsing and drying as above. As the PS nanospheres are negatively charged, they are attracted to the positively charged surface (due to the $\mathrm{ACH}$ ), while they repel other nanospheres. This results in a short range ordered array of PS nanospheres. The distance between first nanoparticle neighbors was controlled by adding an appropriate amount of $\mathrm{NaCl}$ to the nanosphere solution. Afterwards, a $10 \mathrm{~nm}$ thick $\mathrm{Cr}$ film was evaporated by physical vapor deposition (PVD 225, Kurt. J. Lesker). The PS nanospheres were then removed from the sample surface by tape stripping (Nitto Scandinavia AB), which left an array of nanoholes into the $\mathrm{Cr}$ film. The latter was used as etching mask in the subsequent directional oxygen plasma etch (Plasma Therm BatchTop, $2.5 \mathrm{~min}, 50 \mathrm{~W}, 250 \mathrm{mTorr}$ ). At this point $5 \mathrm{~nm}$ of Ti, Fe or $\mathrm{Cu}$ were evaporated using the same PVD system as above. Finally, the mask was removed by lift-off in acetone, followed by rinsing in isopropanol and Milli-Q water and $\mathrm{N}_{2}$ blow-dry. The Ti disks were converted into $\mathrm{TiO}_{2}$ by overnight exposure to air. The Fe disks were converted into $\mathrm{Fe}_{2} \mathrm{O}_{3}$ by thermal oxidation using the same procedure as for the Fe film and $t_{o x}$ of $6 \mathrm{~h}$. The $\mathrm{Cu}$ disks were converted into $\mathrm{Cu}_{2} \mathrm{O}$ by exposure to isotropic oxygen plasma (TePla 300PC, $2 \mathrm{~kW}, 120 \mathrm{~s}$ ). 


\section{XPS measurements}

In order to analyze the chemical state of the elements present in the nanodisks, XPS characterization on $\mathrm{Fe}_{2} \mathrm{O}_{3}+\mathrm{TiO}_{2}, \mathrm{Fe}_{2} \mathrm{O}_{3}+\mathrm{Cu}_{2} \mathrm{O}$ and $\mathrm{Fe}_{2} \mathrm{O}_{3}$ samples was carried out. The results are summarized in Figure S2. As seen panel (a), the $\mathrm{Fe}(2 \mathrm{p})$ peaks are almost identical for the three samples, with the $\mathrm{Fe}\left(2 \mathrm{p}_{3 / 2}\right)$ peak located between 710.74 and $710.79 \mathrm{eV}$, in excellent agreement with $\mathrm{Fe}$ in the $\mathrm{Fe}_{2} \mathrm{O}_{3}$ state. ${ }^{1}$ As the samples were subjected to atmosphere after fabrication, carbon impurities from the air adsorbed on the surface give rise to the $\mathrm{C}(1 \mathrm{~s})$ peak shown in panel $\mathrm{b}$. The size and shape of the $\mathrm{C}(1 \mathrm{~s})$ peak is very similar for all samples with a binding energy between 285.72 and $285.82 \mathrm{eV}$, indicating that there was no individual charging of the samples with respect to each other, nor differences in the types of impurities. Panel c shows the $\mathrm{Ti}(2 \mathrm{p})$ region and as expected, only the sample with $\mathrm{TiO}_{2}$ disks show peaks here. The $\mathrm{Ti}\left(2 \mathrm{p}_{3 / 2}\right)$ peak is located at $458.93 \mathrm{eV}$, in good agreement with $\mathrm{Ti}$ in the $\mathrm{TiO}_{2}$ form. ${ }^{1} \mathrm{The}^{\mathrm{Fe}} \mathrm{O}_{3}+$ $\mathrm{Cu}_{2} \mathrm{O}$ sample in panel d clearly shows $\mathrm{Cu}$ in an oxidized state with the presence of shake-up peaks. The location of $\mathrm{Cu}\left(2 \mathrm{p}_{3 / 2}\right)$ peak is $932.82 \mathrm{eV}$, in good agreement with $\mathrm{Cu}$ in the $\mathrm{Cu}_{2} \mathrm{O}$ form. ${ }^{1}$

\section{Mott-Schottky analysis}

The Mott-Schottky equation used in this work reads:

$$
\frac{A_{\text {contact }}}{C_{\text {bulk }}^{2}}=\frac{2}{\varepsilon_{0} \varepsilon_{r} N_{D}}\left(E-E_{f b}-\frac{k_{B} T}{e}\right)
$$

where: $A_{\text {contact }}$ is the semiconductor/electrolyte contact area, $k_{B}$ is the Boltzmann constant, $T$ is the absolute temperature, $e$ is the elementary charge, $\varepsilon_{0}$ is the permittivity of vacuum, $\varepsilon_{r}$ is the relative permittivity of the semiconductor (estimated to be 19 from a previous work on photoanodes fabricated according to the same procedure used here ${ }^{2}$ ), $N_{D}$ is the density of charge donors in the semiconductor (typically replaced by $N_{A}$ in case of a majority of charge acceptors), and $E_{f b}$ is the flat band potential in the semiconductor. ${ }^{3}$ 


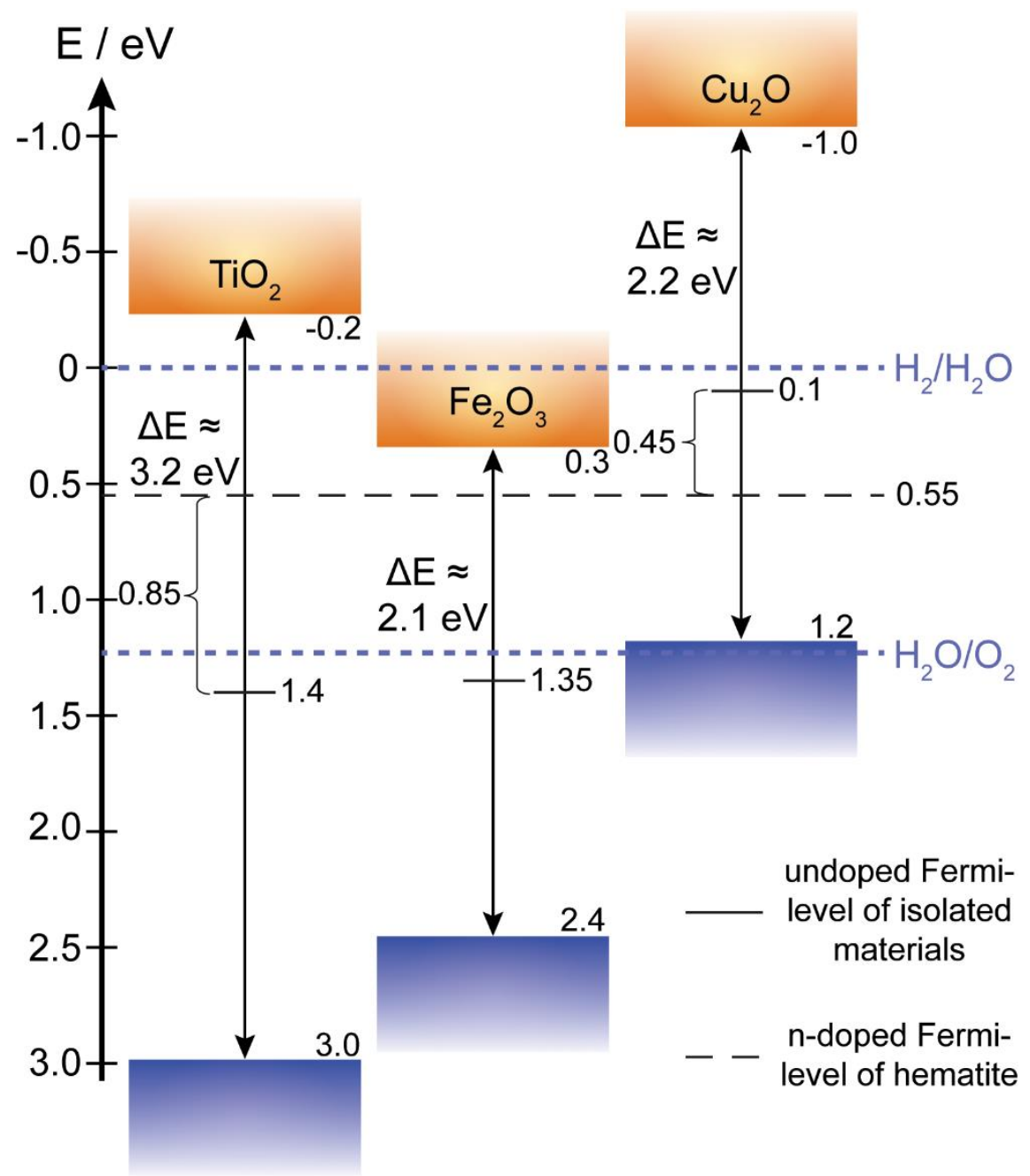

Figure S1. Extension of Figure 1b explaining the origin of the direction of charge transfer, and therefore of the associated dipole-like field, in the case of weakly doped $\mathrm{Fe}_{2} \mathrm{O}_{3}$. We determined $\mathrm{Fe}_{2} \mathrm{O}_{3}$ to be n-doped from the Mott-Schottky, and using the value of the donor density extracted from the Mott-Schottky plot we determined that the Fermi level lies $\sim 0.25 \mathrm{eV}$ below the bottom of the conduction band. This allows the relative Fermi level of $\mathrm{TiO}_{2}$ to be $0.85 \mathrm{eV}$ above the undoped case without changing the charge transfer picture described in the main body of the manuscript. Given that the formation energy of $\mathrm{TiO}_{2}$ is much larger as compared to hematite there should be a thermodynamic driving force to oxidize the $\mathrm{TiO}_{2}$ more as compared to the $\mathrm{Fe}_{2} \mathrm{O}_{3}$, hence, we expect the n-doping should be less pronounced on the $\mathrm{TiO}_{2}$ disks as compared to $\mathrm{Fe}_{2} \mathrm{O}_{3}$. These arguments support the same charge transfer direction as in the case of undoped $\mathrm{Fe}_{2} \mathrm{O}_{3}$. Also, the Fermi energy of the doped $\mathrm{Fe}_{2} \mathrm{O}_{3}$ is lower than that of $\mathrm{Cu}_{2} \mathrm{O}$, which leads to the opposite direction of charge transfer direction and therefore of dipole-like field. 

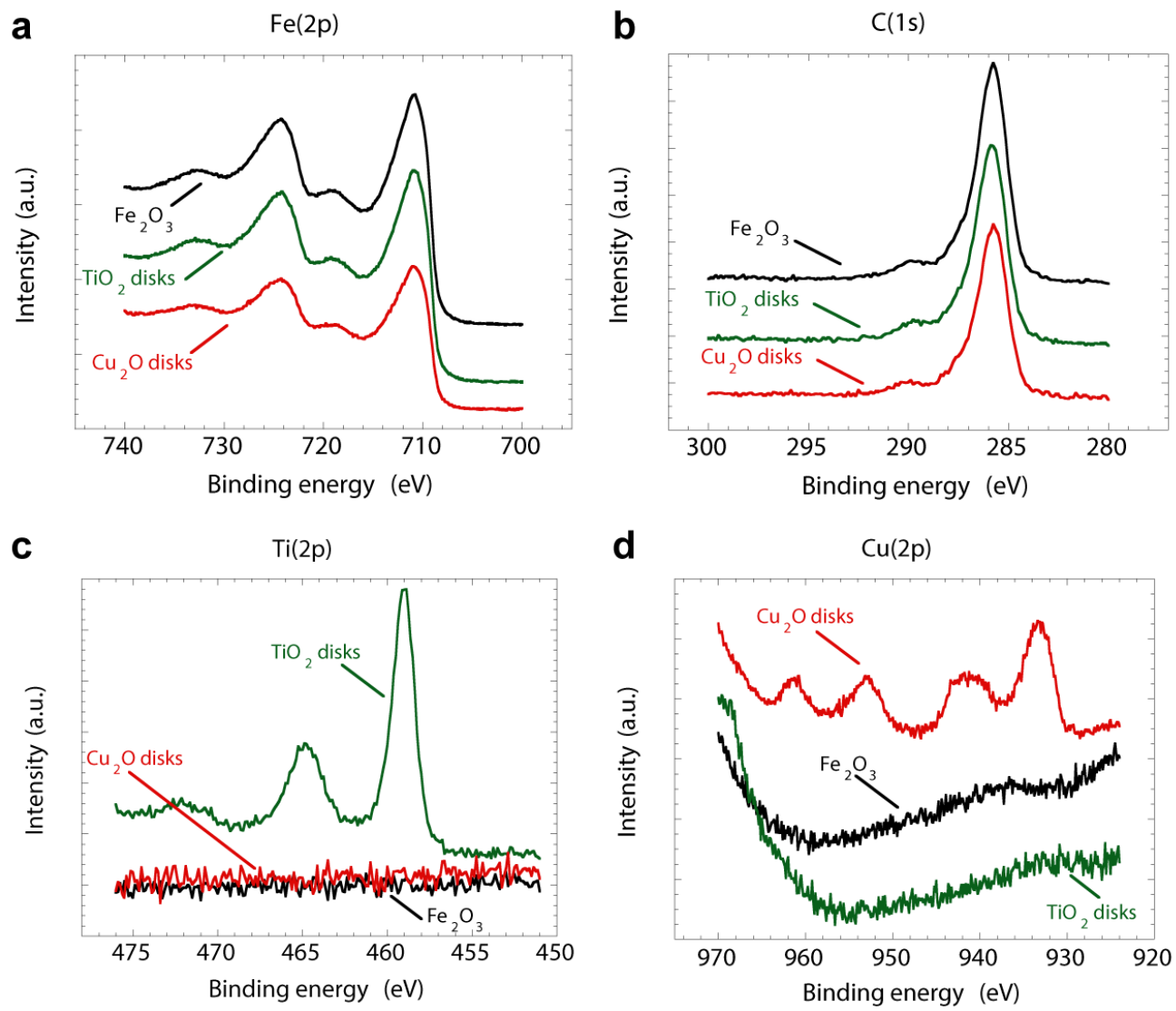

Figure S2. XPS measurements on $\mathrm{Fe}_{2} \mathrm{O}_{3}$ reference sample (black), $\mathrm{Fe}_{2} \mathrm{O}_{3}+\mathrm{TiO}_{2}$ disks (green) and $\mathrm{Fe}_{2} \mathrm{O}_{3}+\mathrm{Cu}_{2} \mathrm{O}$ disks (red). (a) $\mathrm{Fe}(2 \mathrm{p}$ ) peak. (b) $\mathrm{C}(1 \mathrm{~s})$ peak. (c) $\mathrm{Ti}(2 \mathrm{p}$ ) peak. (d) $\mathrm{Cu}(2 \mathrm{p}$ ) peak. The traces have been shifted vertically to ease comparison. 


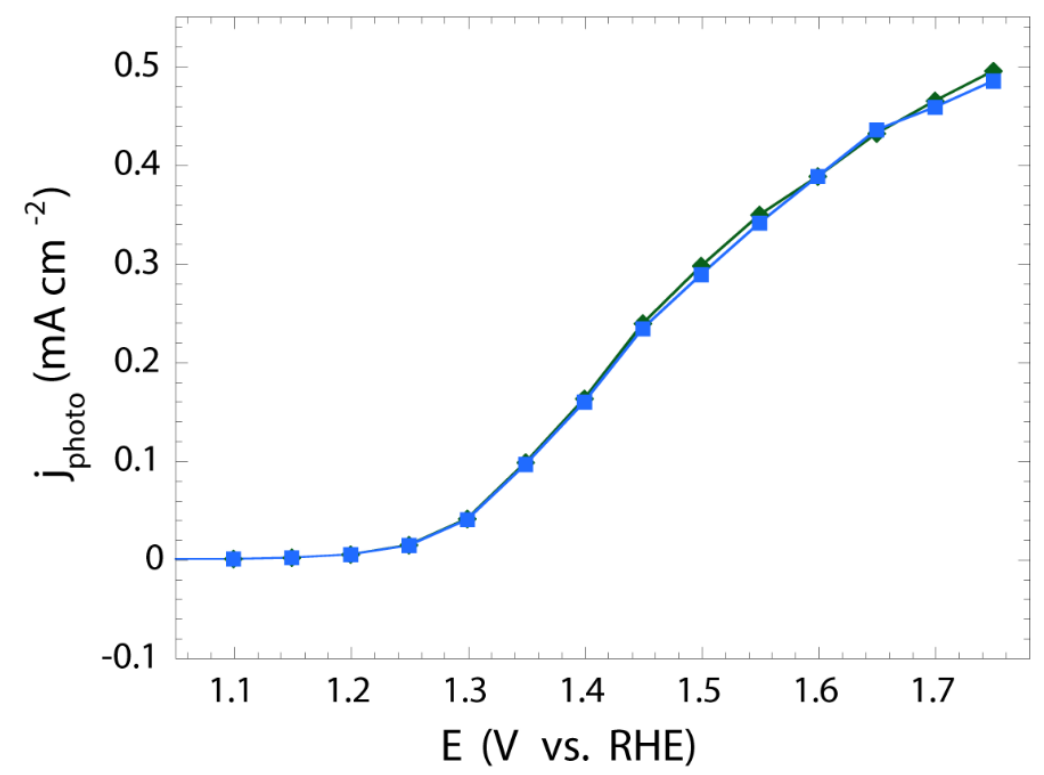

Figure S3. Steady state photocurrent density as a function of applied electrochemical potential and under AM 1.5 solar simulated illumination, on $\mathrm{Fe}_{2} \mathrm{O}_{3}+\mathrm{TiO}_{2}$ disks (green diamonds) and $\mathrm{Fe}_{2} \mathrm{O}_{3}+\mathrm{SiO}_{2}$ disks (blue squares). $\mathrm{Fe}_{2} \mathrm{O}_{3}$ thickness: $25 \mathrm{~nm}$ thick, nanodisks average diameter: 41 $\mathrm{nm}$, thickness: $5 \mathrm{~nm}$, surface coverage: 0.1 . The solid lines are a guide to the eye.

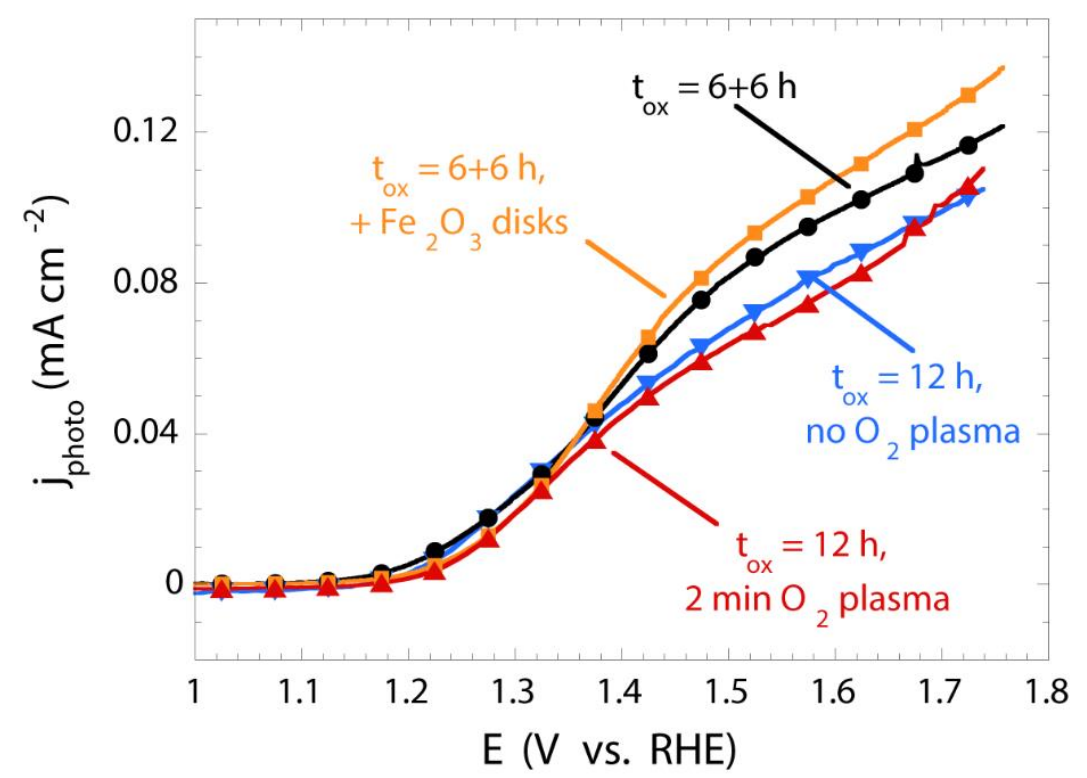

Figure S4. $j$ - $E$ curves for $\mathrm{Fe}_{2} \mathrm{O}_{3}$ samples: reference $\mathrm{Fe}_{2} \mathrm{O}_{3}$ film with $t_{o x}=6+6 \mathrm{~h}$ (two oxidation runs, circles), reference $\mathrm{Fe}_{2} \mathrm{O}_{3}$ film with $t_{o x}=6+6 \mathrm{~h}$ and $\mathrm{Fe}_{2} \mathrm{O}_{3}$ disks on top (squares), reference $\mathrm{Fe}_{2} \mathrm{O}_{3}$ film with $t_{o x}=12 \mathrm{~h}$ (one oxidation run, downward triangles) and reference $\mathrm{Fe}_{2} \mathrm{O}_{3}$ film with $t_{o x}=12 \mathrm{~h}$ after the same 2 minutes $\mathrm{O}_{2}$ plasma treatment to oxidize $\mathrm{Cu}$ disks into $\mathrm{Cu}_{2} \mathrm{O}$ (upward triangles). 


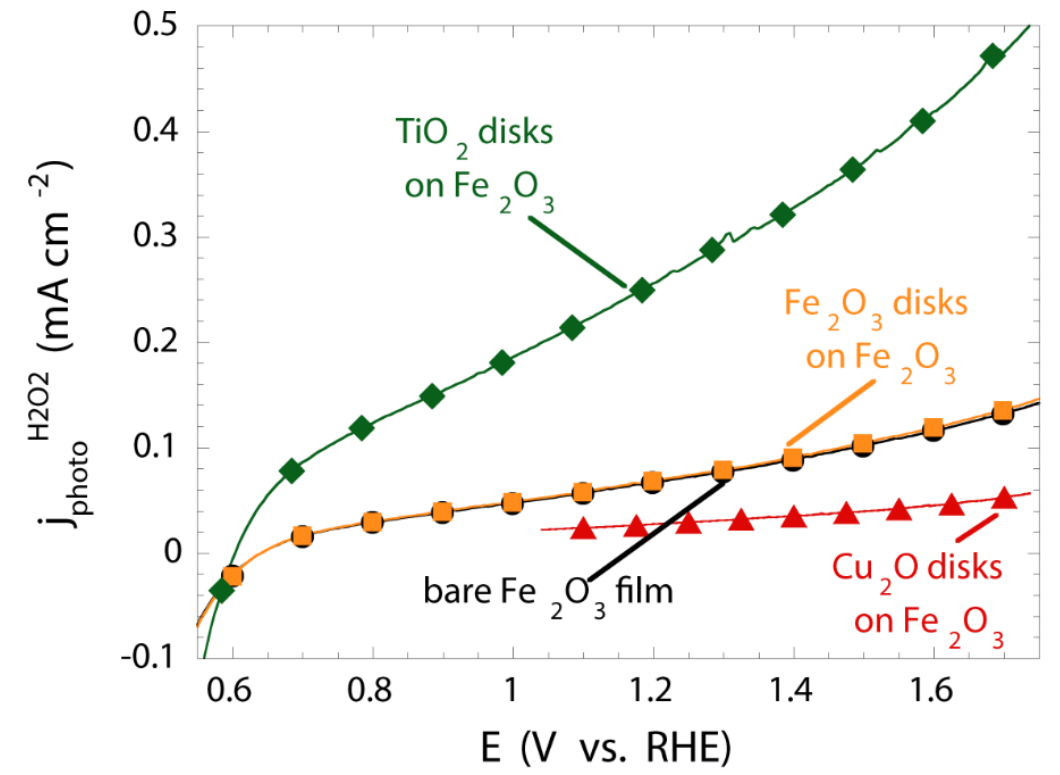

Figure S5. Photocurrent density from cyclic voltammetry under AM 1.5 solar simulated illumination, in $0.1 \mathrm{M} \mathrm{KOH}+0.3 \mathrm{M} \mathrm{H}_{2} \mathrm{O}_{2}$, for bare $\mathrm{Fe}_{2} \mathrm{O}_{3}$ film (circles), $\mathrm{Fe}_{2} \mathrm{O}_{3}+\mathrm{Fe}_{2} \mathrm{O}_{3}$ disks (squares), $\mathrm{Fe}_{2} \mathrm{O}_{3}+\mathrm{TiO}_{2}$ disks (diamonds) and $\mathrm{Fe}_{2} \mathrm{O}_{3}+\mathrm{Cu}_{2} \mathrm{O}$ disks (triangles).

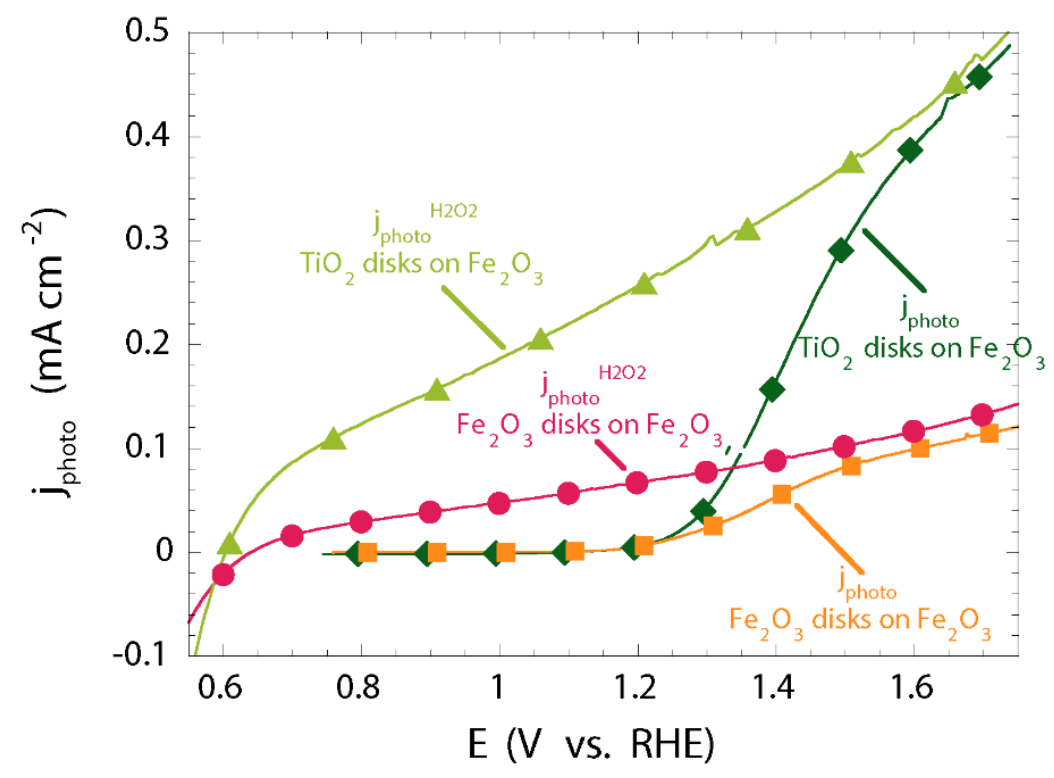

Figure S6. Comparison of photocurrent density from cyclic voltammetry under AM 1.5 solar simulated illumination, with and without additional $\mathrm{H}_{2} \mathrm{O}_{2}$, for $\mathrm{Fe}_{2} \mathrm{O}_{3}+\mathrm{Fe}_{2} \mathrm{O}_{3}$ disks (circles and squares respectively), and for $\mathrm{Fe}_{2} \mathrm{O}_{3}+\mathrm{TiO}_{2}$ disks (triangles and diamonds, respectively). 


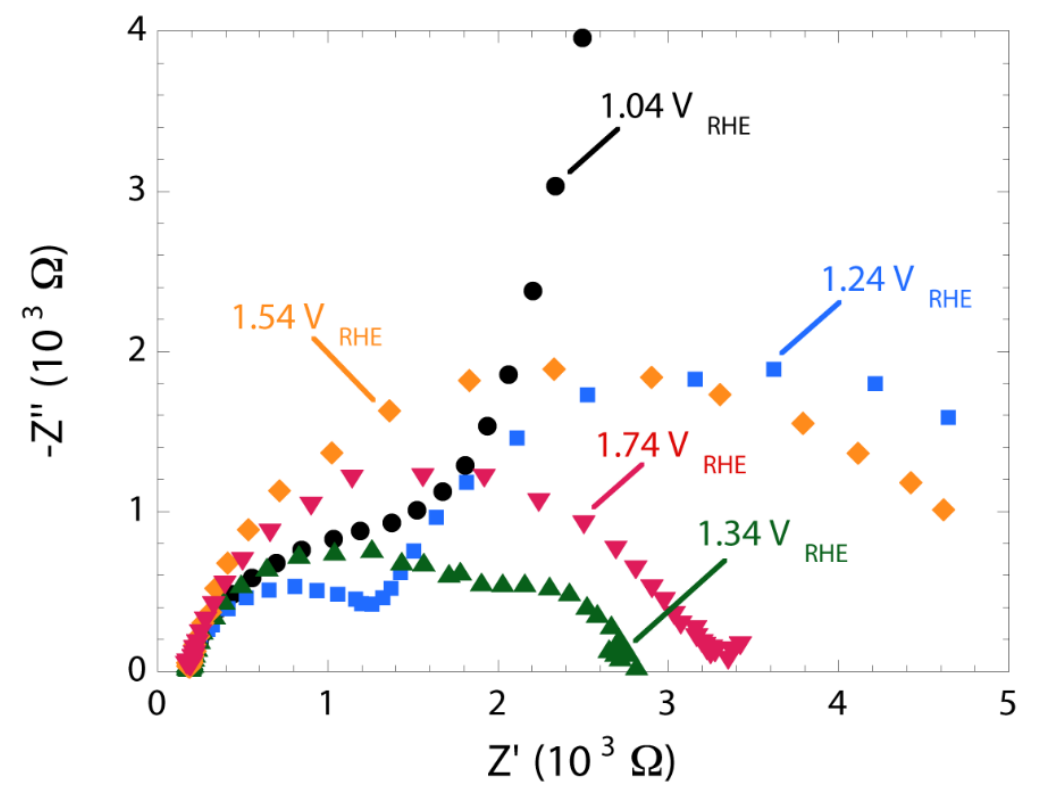

Figure S7. Nyquist plots (real component vs. negative imaginary component of the total impedance $Z$ ) for $\mathrm{Fe}_{2} \mathrm{O}_{3}+\mathrm{TiO}_{2}$ nanodisks at different values of potential $E$.

a

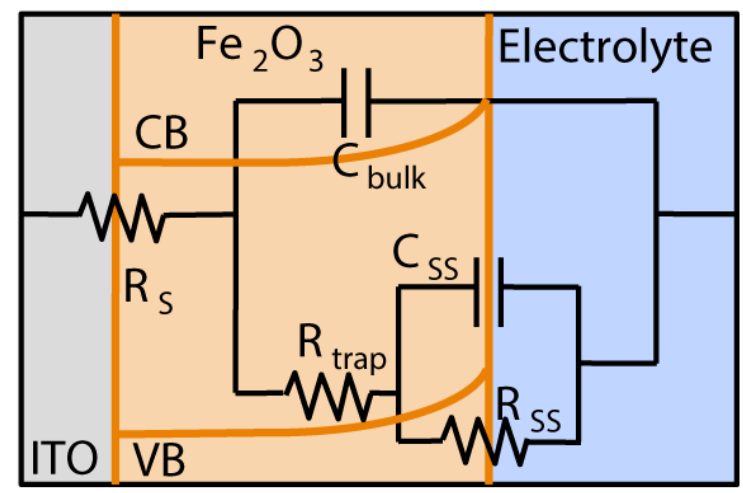

b

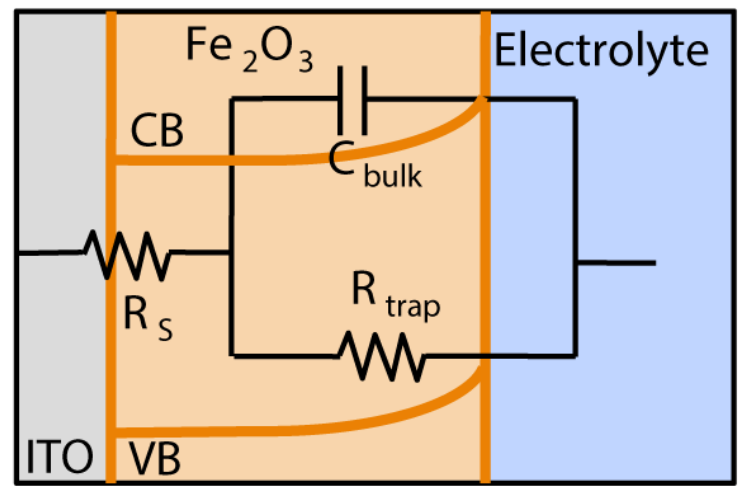

Figure S8. Equivalent circuits used to fit the Nyquist plots. (a) Hamann's circuit with surface states, used for $E<1.6 \mathrm{~V}_{\mathrm{RHE}}$ under illumination. (b) Randle's circuit without surface states used for $E \geq 1.6 \mathrm{~V}_{\mathrm{RHE}}$ under illumination and at all potentials in the dark. 

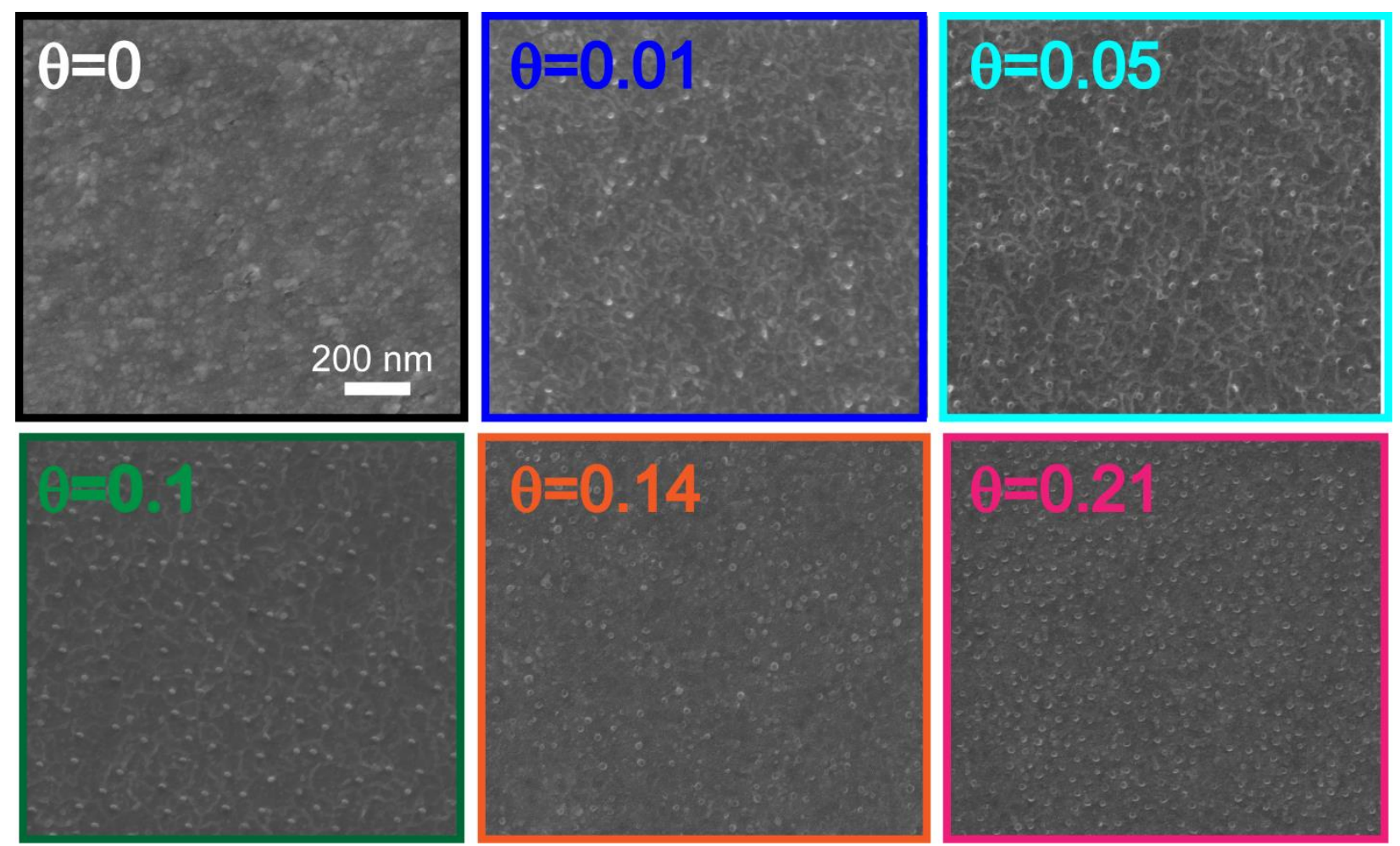

Figure S9. Top-view SEM micrographs of $\mathrm{Fe}_{2} \mathrm{O}_{3}+\mathrm{TiO}_{2}$ nanodisks, with increasing surface coverage of the nanodisks, $\theta$, from 0 (corresponding to a bare $\mathrm{Fe}_{2} \mathrm{O}_{3}$ film) to 0.21 . The nanodisks are not obvious to identify due to their small thickness and to the poor atomic contrast between $\mathrm{Fe}$ and Ti.
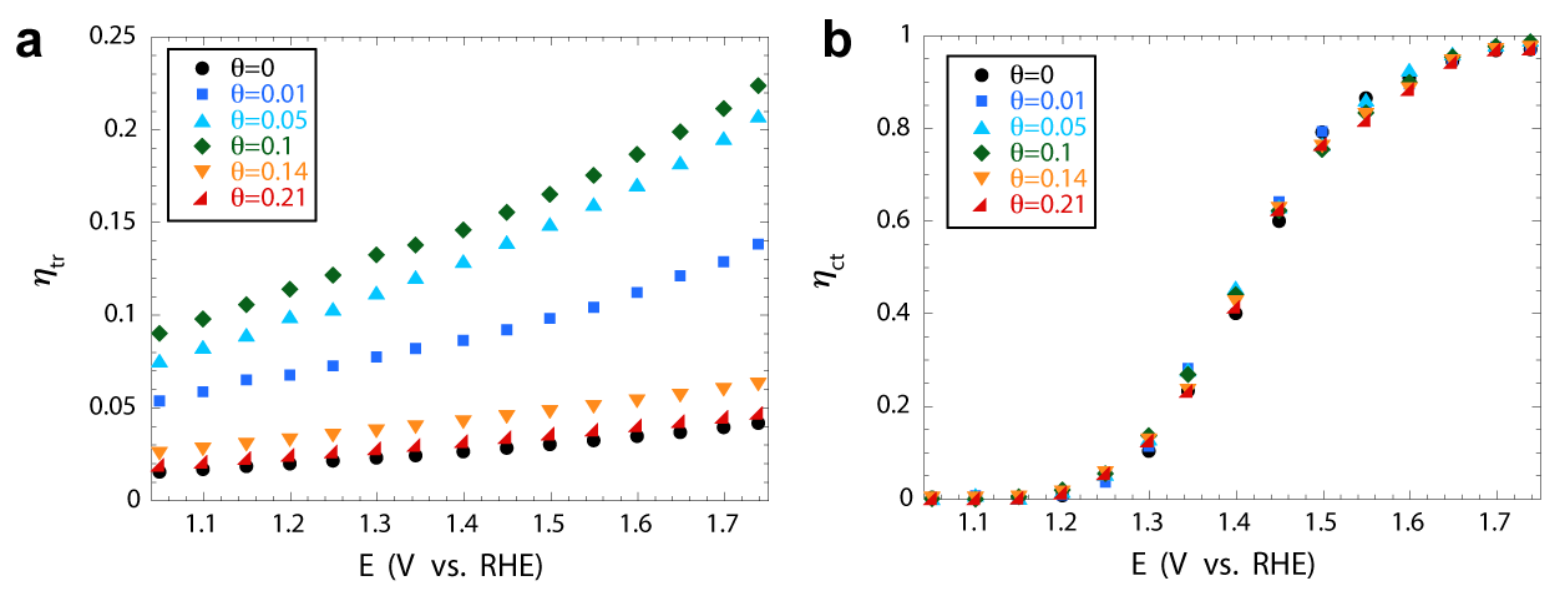

Figure S10. (a) Charge transport efficiency $\eta_{t r}$ within the photoanode as function of $E$ for different surface coverage $\theta$ of $\mathrm{TiO}_{2}$ nanodisks: $\theta=0$ (circles), $\theta=0.01$ (squares), $\theta=0.05$ (upward triangles), $\theta=0.1$ (diamonds), $\theta=0.14$ (downward triangles) $\theta=0.21$ (rectangular triangles). (b) Semiconductor/electrolyte charge transfer efficiency $\eta_{c t}$ as function of $E$. 


\section{Supplementary References}

(1) Moulder, J. F.; Stickle, W. F.; Sobol, P. E.; Bomben, K. D. Handbook of X-ray

Photoelectron Spectroscopy; Perkin Elmer Corporation: Minneapolis, 1992.

(2) Iandolo, B.; Zhang, H.; Wickman, B.; Zorić, I.; Conibeer, G.; Hellman, A. RSC Adv. 2015, 5,61021 .

(3) Chen, Z.; Dinh, H. N.; Miller, E. Photoelectrochemical Water Splitting; SpringerBriefs in Energy; Springer New York: New York, NY, 2013. 